\title{
GLOBALIZACIJA IN RAZVOJ SLOVENSKIH MEST
}

\author{
Mirko Pak*
}

\section{Izvleček}

Razvoj slovenskih mest je neenakomeren, pogojen z njihovimi podedovanimi in na novo pridobljenimi funkcijami. In ker gre vedno bolj za razvoj mestnih aglomeracij, je prednost ljubljanske mestne aglomeracije pred drugimi še toliko večja. Sledijo še nekatera druga večja mesta, $v$ glavnem položajno opredeljena. Razvojne razlike in $\mathrm{s}$ tem povezana problematika so prikazane v prispevku.

Ključne besede: Ljubljana, Slovenija, urbanizacija, regionalni razvoj, globalizacija

\section{GLOBALIZATION AND DEVELOPMENT OF SLOVENE CITIES}

\section{Abstract}

Development of Slovene cities is non-uniform and depends on their functions, inherited as well as newly acquired. Development of city agglomeration is more and more present, therefore priority of city agglomeration of Ljubljana is even bigger. Some other bigger cities are following, mostly defined by their location. Differences in development together with related development problems are presented in the article.

Key words: Ljubljana, Slovenia, urbanization, regional development, globalization

\footnotetext{
* Dr. prof., Oddelek za geografijo, Filozofska fakulteta Univerza v Ljubljani, Aškerčeva 2,
} SI 1000 Ljubljana, Slovenija 


\section{RAZVOJ MEST IN GLOBALIZACIJA}

Za najnovejši razvoj mest sta $\mathrm{v}$ vsebinskem in regionalnem pogledu značilna njihova hitra rast in preobrazba. In če govorimo o vsesplošnem naglem razvoju mest, vendarle ne moremo mimo splošnega spoznanja o njihovi neenakomerni rasti in praviloma tudi o izraziti razvojni polarizaciji, soodvisni od njihovega položaja $v$ hierarhiji naselij. In ker ena prednost pogojuje drugo, vodi to $\mathrm{k}$ vedno močnejši koncentraciji, globalno $\mathrm{v}$ splošnem in regionalnem pogledu. Ker to spremlja pospešena suburbanizacija podprta $\mathrm{z}$ razvojem komunikacij, se ta koncentracija manifestira tudi $\mathrm{v}$ prostorskem širjenju mest ter v njihovem preraščanju $\mathrm{v}$ funkcionalne aglomeracije. K. Stiglbauer in K. Wolf sta že pred skoraj dvajsetimi leti na primeru avstrijskih in nemških mest opredelila ta proces soodvisnosti z nadregionalnimi funkcijami, kot o temelju izrazite razvojne koncentracije ne le pri največjih, temveč tudi pri manjših centralnih naseljih. To pa pomeni razvojno odvisnost mest od vedno večjega prostora in od vedno močnejših subjektov, na primer multinacionalnih družb, ki so v Sloveniji najmočneje prisotne na področju trgovine. Izrazita je na primer takšna soodvisnost in s tem povezana selektivna rast mest $\mathrm{v}$ ZDA ali $\mathrm{v}$ nemških mestih, kjer so še pred leti drugače vrednoteni dejavniki podpirali razvoj večjega števila polov. Lep primer je avtomobilska industrija, ki se seli $\mathrm{v}$ »sekundarna « središča, $\mathrm{v}$ » primarna« pa eleketronska in druge najvišje kategorije proizvodnje.

Takšen neenakomeren selektivni razvoj mest je značilen tako za razvita kot za nerazvita okolja. Lep primer je razvoj mest v nekdanjih »vzhodno-srednjeevropskih « deželah, kjer je ta polarizacija po političnih in gospodarskih spremembah še mnogo bolj izrazita. Zato ni slučaj povečano zanimanje $\mathrm{v}$ urbani geografiji za globalizacijsko problematiko, čemur je bilo dano težišče tudi na zasedanju komisije Mednarodne geografske zveze »Urban development and Urban Life« leta 1998 v Sinaji (Romunija), vsebinsko pa je bilo prisotno tudi že dve leti poprej na njenem zasedanju v Ciudad de Mexico.

\section{RAZVOJ SLOVENSKIH MEST}

Tudi slovenska mesta doživljajo selektiven razvoj. Začetki tega pa segajo že v osemdeseta leta. Zaradi političnih in družbeno-ekonomskih sprememb po letu 1990, so v njihovem razvoju sicer prisotni razvojni elementi »vzhodnoevropskih mest«, zaradi specifičnega predhodnega razvoja Slovenije v pogledu večje policentričnosti in tržne naravnanosti gospodarstva, pa je njihov razvoj precej bližji razvoju zahodnevropskih mest. Ob tem osnovne razvojne značilnosti še vedno veljajo : prednjači razvoj državnega središč (prestolnice), sledijo nekatera mesta ob slovenskem razvojnem polmesecu in ob obali, zaostajajo pa obrobno ležeča mesta, obmejna mesta in z deindustrializacijo močno prizadeta industrijska središča. Nadaljuje se klasični razvojni model mest $\mathrm{v}$ smislu regionalno razvojnega modela. Relativno gledano so 
razvojne spremembe sicer prisotne $\mathrm{v}$ vseh mestih, vendar omejene $\mathrm{v}$ glavnem na določene strukturne spremembe, ne pa na njihov enakovreden in skladen splošni razvoj, vštevši suburbanizacijo ki je, kot med drugim ugotavljata v svojih študijah tako Ravbar kot Vrišer, posledica in ogledalo regionalnega in urbanega razvoja (Ravbar ,1995; Vrišer, 1999).

Med slovenskimi mesti se razlike še povečujejo, kar je večinoma položajno in funkcijsko pogojeno. Prednost pomeni položaj mesta ob razvojno najbolj ugodnih točkah oziroma smereh, povezano s čim večjim številom in kvalitetnejšimi funkcijami. Vrednotenje ali opredeljevanje mest s številom mestnih funkcij, poklicev ali podobno, je $\mathrm{v}$ sedanjem razvoju slovenskih mest tudi praktično smiselno, saj kopičenje terciarnih dejavnosti zaostruje regionalne razlike in krepi centre moči in odločanja (Rus,Stanič, 1996). Praviloma razvojno še vedno zaostajajo mesta, ki so še $\mathrm{v}$ osemdesetih letih imela izrazito ali poudarjeno industrijsko usmeritev, pa čeprav se je zaradi deindustrializacije njena vloga zmanjšala. Tako so na primer leta 1996 imela nekatera slovenska mesta zelo spremenjen delež v industriji zaposlenega prebivalstva : le 14,1\% v Kopru, 19,6\% v Ljubljani, 22,3\% v Celju, 28,9\% na Ptuju, $29,6 \%$ v Mariboru, 34,5\% na Jesenicah in $45,4 \%$ v Trbovljah ter kar 52,5\% v Kranju, ki je med vsemi slovenskimi mesti svojo industrijo najuspešneje revitaliziral. Obratno je $\mathrm{z}$ mesti, ki se uspešneje vključujejo v globalizacijske tokove, pri čemer prednjačita zlasti Ljubljana in Koper.

V Ljubljani živi 16\% slovenskega prebivalstva, že v naslednjem mestu po velikosti Mariboru le $5 \%$ in $\mathrm{v}$ mestih tretje velikostne kategorije le po $2 \%$. Zaradi načina poselitve slovenskega prostora koncentracija prebivalstva sicer ni ekstremna, toda že razklika do naslednjih večjih naselij kaže na ekstremne razlike med Ljubljano in drugimi slovenskimi mesti. Razlika se zaradi ugodnejšega prebivalstvenega razvoja Ljubljane, kjer je prebivalstvo v obdobju 1981-91 naraslo za 18,1\% kot tudi v samem ljubljanskem zgostitvenem območju, še povečuje. Ljubljani sosednje občine imajo vse tudi v zadnjih letih pozitivni selitveni saldo. Že na območju Maribora in Celja prebivalstveni razvoj močno zaostaja, $v$ glavnem pa ga zaradi negativnega naravnega prirastka in uravnoteženega selitvenega salda praktično ni. Enako velja tudi za njihova suburbana in širša vplivna območja, vključujoč manjša urbana središča. Triletni naravni prirastek (1995-97) je v sami Ljubljani sicer negativen za 41 oseb, v njegovem suburbanem območju pa pozitiven; močno negativen je v Mariboru za 774 oseb, v Celju za 104 osebe, v Trbovljah za 124 oseb in tudi v Kopru za 119 oseb. Seveda pa bolj neposredno kaže razvojne prilike selitveni saldo, ki skupaj z naravnim prirastkom kaže zmanjšanje števila prebivalstva v Celju za 230, v Mariboru za 1961, Murski Soboti za 205 oseb itd. Predvsem pa je praviloma negativen v gospodarsko manj uspešnih in pozitiven v gospodarsko bolj uspešnih občinah. Precejšnje so med mesti razlike v delovnih mestih, kar je temelj razvoju mestnega prebivalstva. V bistvu so že pred letom 1990 nakazani razvojni trendi le še poglobili tako razlike med različno velikimi in razvojno uspešnimi mesti, kot tudi v regionalnem pogledu. 
Odločilna je seveda gospodarska koncentracija oziroma razlikovanje, ki je večinoma podedovana in se je po letu 1990 samo močno okrepila, vsebinsko močno razširila in internacionalizirala. Namestitev bank, zavarovalnic, domačih in tujih firm, zastopstev, diplomatskih predstavništev in drugega skupaj z državnimi ustanovami je prvenstveno usmerjeno v Ljubljano, kjer ima sedež kar 13 ali okoli polovice slovenskih bank, v Mariboru le 3 in $\mathrm{v}$ drugih mestih največ po ena. Tekoči integracijski tokovi to koncentracijo še poglabljajo. Podobno je s koncentracijo tujih zastopstev in firm. Leta 1990 je bilo v Ljubljani 144 podjetij ustanovljenih $\mathrm{z}$ mešanim kapitalom in registrirana so bila 3 tuja predstavništva ; leta 1996 pa 1599 in 395 (44\% v občini Center, kar zopet kaže na koncentracijo) od tega 48,6\% poslovnih in finančnih storitev ter 31,9\% trgovin. Končno premore Ljubljana kar 4 krat več podjetij in družb (prebivalcev ima le 2,5 krat) več kot Maribor. To mestu poleg drugega prinaša delovna mesta nadpovprečne kvalitete, posledično pa to pomeni koncentracijo prebivalstva in kupne moči, tudi $\mathrm{v}$ relativnem pogledu mnogo hitreje kot $\mathrm{v}$ drugih mestih. Da vpliva to tudi na večja strukturna razhajanja, kar se manifestira tudi $v$ številu prebivalstva aglomeracije, pa je znano tudi iz drugih razvitih evropskih sredin.

Selektivni razvoj slovenskih mest je močno povezan $\mathrm{s}$ tujimi investicijami. $\mathrm{V}$ Ljubljano in $\mathrm{v}$ druga večja mesta so ta seveda bistveno večja. Kar 35\% večletnih tujih investicij v Slovenijo je končalo $\mathrm{v}$ Ljubljani in dodatno še $\mathrm{v}$ njeni okolici. Raziskave Domžal so pokazale tudi številne tuje investicije v drobno gospodarstvo, kar je zopet v prid razvoju Ljubljane in njene aglomeracije (Gosar, 1994).Zato tudi niso slučajne velike razlike $\mathrm{v}$ ceni prostora in najemnin med Ljubljano in drugimi slovenskimi mesti. Med Ljubljano in Koprom ter Mariborom in Celjem je bilo razmerje v prid prvih dveh mest do 1,7 (Statistični, 1997) ; realni trg nepremičnin in najemnin pa kaže tudi do dvakratne razlike.

\section{SKLEP}

Končno se razvoj naših mest manifestira tudi v njihovem gospodarskem, funkcijskem, morfološkem in socialnem razvoju, ustroju in preobrazbi : v preusmeritvi drobne industrije, v razvoju storitvenih dejavnosti, infrastrukture, v umiku stanovanjskih pred nestanovanjskimi funkcijami in površinami ter v socialni preobrazbi. Ker so v večjih mestih gornje spremembe znatnejše, se razlike $v$ opremljenost mest le še povečujejo. $\mathrm{V}$ razvoju prednjačijo Ljubljana in deloma druga večja slovenska mesta,kjer se bivša funkcijska, socialnogeografska, pa tudi zgradbena heterogenost zmanjšuje in podobno kot $\mathrm{V}$ zahodnoevropskih mestih se njihovi posamezni predeli postopoma homogenizirajo. 


\section{LITERATURA}

- Anton Gosar, Mirko Pak, Angelca Rus, 1994, Občina Domžale, elementi regionalnega razvoja. Arbeitsmateriallien zur Raumordnung und Raumplanung. Heft 14o, Bayreuth, s. 1-25.

- Mirko Pak, 1995, Socialnogeografska zgradba slovenskih mest na kvalitetnem prehodu. Dela 11, Ljubljana, s. 121-129.

- Marjan Ravbar, 1995, Zasnove poselitve v luči regionalnega razvoja. Ib Revija XXIX, št. 12-13, Ljubljana, s. 21-35.

- Angelca Rus, Ivan Stanič, 1996, Storitvene dejavnosti in regionalni razvoj primer Ljubljane in ljubljanske mestne regije. IB Revija XXX, št.7, Ljubljana.

- Statistični letopis R. Slovenije 1997. Ljubljana.

- Klau Wolf, Karl Stiglbauer, 1984, Zum System und zur dynamik hochrangiger Zentren im nationalen und internationalen Massstab.

\section{GLOBALIZATION AND DEVELOPMENT OF SLOVENE CITIES}

\section{Summary}

Development of cities has always been dependent upon their specific position in hierarchy of central settlements. With faster economical development in the latest period as well as stronger regional connection and combination of social economic factors, more or less balanced development currents began to change more and more in sense of bigger polarization. Development of cities was becoming more and more dependent on bigger space, not only of national, but also of international character. Reconstruction of Porurje or its cities offers good example for such kind of development; such example could most probably not be expected in Zgornja Šlezija or in other similar areas of former countries of Eastern part of Middle Europe. Car manufacture also moved from the most powerful to less developed centers. Almost twenty years ago J. Stiglbauer and K. Wolf pointed out in a special section of German federal geography congress in Munchen, the meaning of "over-regional functions" for development of cities. Some researches in the said scope were executed also in Slovenia and today it represents one of the basic factors of urban development.

Regression of secondary and prosperity of tertiary sector strongly changed and also ruined development relations among Slovene cities, level of globalization representing one of the crucial factors, or their connection with wider, international development factors. Ljubljana as the capital is certainly holding a special position. Development of cities depends also on some other factors, such as geographical position (traffic), development level of neighborhood on this and other side of the board, economic power of the city, its socio-economic structure and management functions, which results in problematic division of Slovenia into provinces. 